\title{
Corrigendum: Identification of Hypoxia Induced Metabolism Associated Genes in Pulmonary Hypertension
}

\begin{abstract}
Yang-Yang $\mathrm{He}^{1}$, Xin-Mei Xie ${ }^{1}$, Hong-Da Zhang ${ }^{2}$, Jue $\mathrm{Ye}^{2}$, Selin Gencer ${ }^{3}$, Emiel P. C. van der Vorst ${ }^{3,4,5,6,7}$, Yvonne Döring ${ }^{3,4,8}$, Christian Weber ${ }^{3,4,9,10}$, Xiao-Bin Pang ${ }^{1}$, Zhi-Cheng Jing ${ }^{11}$, Yi Yan ${ }^{3,4 * t}$ and Zhi-Yan $\mathrm{Han}^{2 * t}$

${ }^{1}$ School of Pharmacy, Henan University, Kaifeng, China, ${ }^{2}$ State Key Laboratory of Cardiovascular Disease and FuWai Hospital, Chinese Academy of Medical Sciences and Peking Union Medical College, Beijing, China, ${ }^{3}$ Institute for Cardiovascular Prevention (IPEK), Ludwig-Maximilians-University Munich, Munich, Germany, ${ }^{4}$ DZHK (German Centre for Cardiovascular Research), Partner Site Munich Heart Alliance, Munich, Germany, Interdisciplinary Center for Clinical Research (IZKF), RWTH Aachen University, Aachen, Germany, ${ }^{6}$ Institute for Molecular Cardiovascular Research (IMCAR), RWTH Aachen University, Aachen, Germany, ${ }^{7}$ Department of Pathology, Cardiovascular Research Institute Maastricht (CARIM), Maastricht University Medical Centre, Maastricht, Netherlands, ${ }^{8}$ Department of Angiology, Swiss Cardiovascular Center, Inselspital, Bern University Hospital, University of Bern, Bern, Switzerland, ${ }^{9}$ Department of Biochemistry, Cardiovascular Research Institute Maastricht (CARIM), Maastricht University Medical Centre, Maastricht, Netherlands, ${ }^{10}$ Munich Cluster for Systems Neurology (SyNergy), Munich, Germany, ${ }^{11}$ State Key Laboratory of Complex, Severe, and Rare Diseases, and Department of Cardiology, Peking Union Medical College Hospital, Chinese Academy of Medical Sciences and Peking Union Medical College, Beijing, China
\end{abstract}

Keywords: pulmonary hypertension, hypoxia, metabolism associated genes, metabolomics, transcriptomics

\section{A Corrigendum on}

Identification of Hypoxia Induced Metabolism Associated Genes in Pulmonary Hypertension by He Y.-Y., Xie X.-M., Zhang H.-D., Ye J., Gencer S., van der Vorst E. P. C., Döring Y., Weber C., Pang X.-B., Jing Z.-C., Yan Y., and Han Z.-Y. (2021). Front. Pharmacol. 12:753727. doi: 10.3389/fphar.2021. 753727

${ }^{\text {t}}$ These authors have contributed equally to this work and share last authorship

Specialty section: This article was submitted to Respiratory Pharmacology, a section of the journal

Frontiers in Pharmacology

Received: 06 November 2021 Accepted: 26 November 2021 Published: 15 December 2021

Citation:

He $Y$-Y, Xie X-M, Zhang H-D, Ye J, Gencer $S$, van der Vorst EPC, Döring $Y$, Weber $C$, Pang $X-B$, Jing Z-C, Yan $Y$ and $\operatorname{Han} Z-Y$ (2021) Corrigendum: Identification of Hypoxia Induced Metabolism Associated Genes in Pulmonary Hypertension.

Front. Pharmacol. 12:810178. doi: 10.3389/fphar.2021.810178
In the original article, there was a mistake in the citation as published. In the citation, commas were missing between "He Y-Y and Xie X-M, Xie X-M and Zhang H-D, Zhang H-D and Ye J, Pang X-B and Jing Z-C, Jing Z-C and Yan Y". The corrected citation should be "He Y-Y, Xie X-M, Zhang H-D, $Y$ Y J, Gencer S, van der Vorst EPC, Döring Y, Weber C, Pang X-B, Jing Z-C, Yan Y and Han Z-Y (2021) Identification of Hypoxia Induced Metabolism Associated Genes in Pulmonary Hypertension. Front. Pharmacol. 12:753727. doi:10.3389/fphar.2021.753727."

In addition, there was a mistake in Figure 6 as published. The $\mathrm{x}$-axis labels for Figures $6 \mathrm{~B}$ and $\mathbf{6 C}$ were incorrectly labelled as "specficity". The corrected Figure 6 appears below.

The authors apologize for this error and state that this does not change the scientific conclusions of the article in any way. The original article has been updated.

Publisher's Note: All claims expressed in this article are solely those of the authors and do not necessarily represent those of their affiliated organizations, or those of the publisher, the editors and the reviewers. Any product that may be evaluated in this article, or claim that may be made by its manufacturer, is not guaranteed or endorsed by the publisher.

Copyright $\odot 2021$ He, Xie, Zhang, Ye, Gencer, van der Vorst, Döring, Weber, Pang, Jing, Yan and Han. This is an open-access article distributed under the terms of the Creative Commons Attribution License (CC BY). The use, distribution or reproduction in other forums is permitted, provided the original author(s) and the copyright owner $(s)$ are credited and that the original publication in this journal is cited, in accordance with accepted academic practice. No use, distribution or reproduction is permitted which does not comply with these terms. 


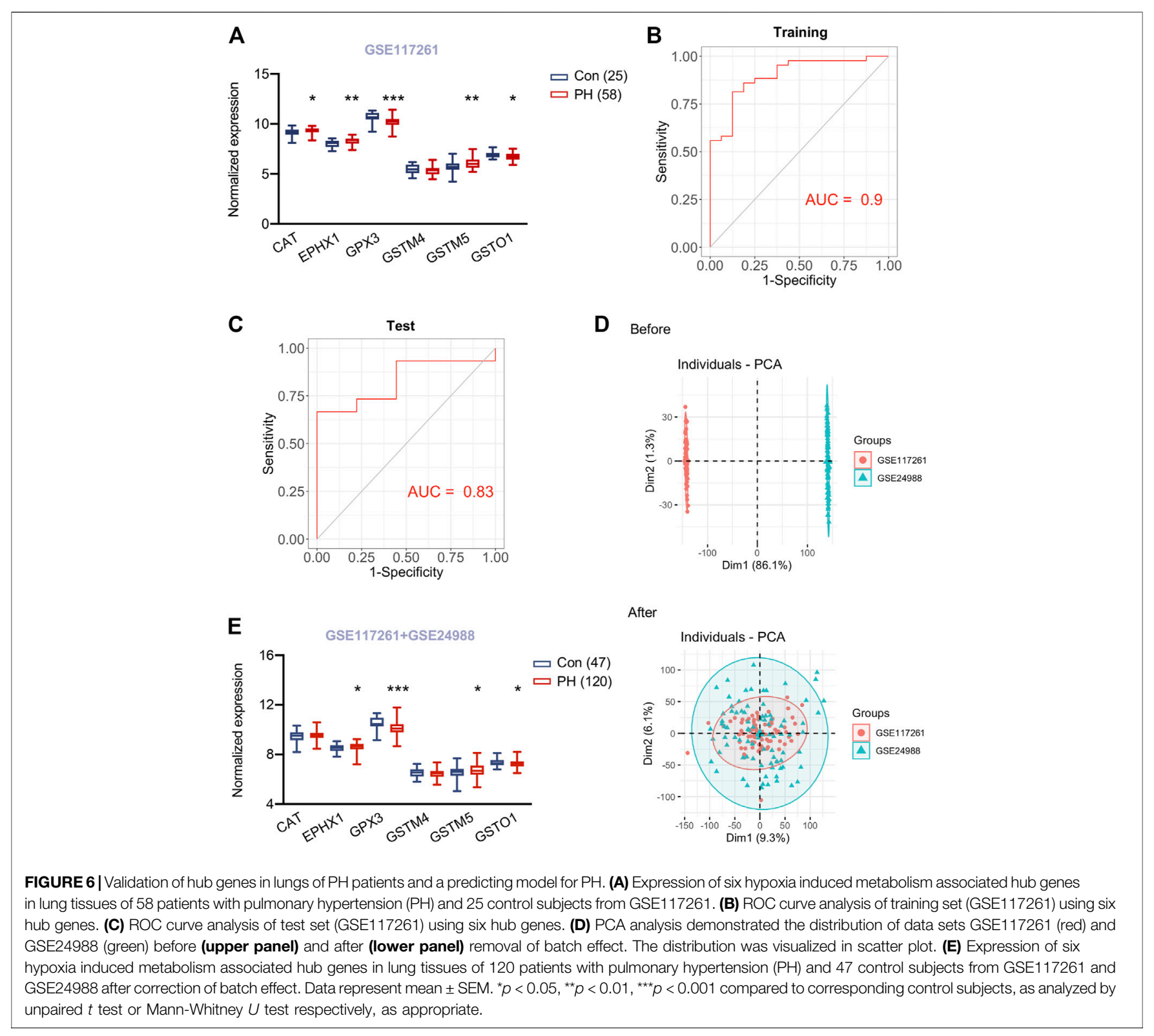

